\title{
Anti-cancer effects of Gynostemma pentaphyllum (Thunb.) Makino (Jiaogulan)
}

Yantao Li, Wanjun Lin, Jiajun Huang, Ying Xie and Wenzhe Ma*

\begin{abstract}
Gynostemma pentaphyllum (Thunb.) Makino (GpM) (Jiaogulan) has been widely used in Chinese medicine for the treatment of several diseases, including hepatitis, diabetes and cardiovascular disease. Furthermore, GpM has recently been shown to exhibit potent anti-cancer activities. In this review, we have summarized recent research progress on the anti-cancer activities and mechanisms of action of $\mathrm{GpM}$, as well as determining the material basis for the anti-cancer effects of GpM by searching the PubMed, Web of Science and China National Knowledge Infrastructure databases. The content of this review is based on studies reported in the literature pertaining to the chemical components or anti-cancer effects of GpM up until the beginning of August, 2016. This search of the literature revealed that more than 230 compounds have been isolated from GpM, and that most of these compounds (189) were saponins, which are also known as gypenosides. All of the remaining compounds were classified as sterols, flavonoids or polysaccharides. Various extracts and fractions of $\mathrm{GpM}$, as well as numerous pure compounds isolated from this herb exhibited inhibitory activity towards the proliferation of cancer cells in vitro and in vivo. Furthermore, the results of several clinical studies have shown that GpM formula could have potential curative effects on cancer. Multiple mechanisms of action have been proposed regarding the anti-cancer activities of GpM, including cell cycle arrest, apoptosis, inhibition of invasion and metastasis, inhibition of glycolysis and immunomodulating activities.
\end{abstract}

\section{Background}

Cancer is the world's leading cause of death, accounting for 8.2 million deaths in 2012, and it is expected that the annual number of global cancer cases will rise from 14 million in 2012 to 22 million within the next two decades [1]. The isolation and evaluation of anti-cancer agents and lead compounds from natural resources represents a traditional and effective approach for the development of new drugs for the treatment of cancer [2,3], as exemplified by Paclitaxel, which was derived from Taxus brevifolia $[3,4]$.

Gynostemma pentaphyllum (Thunb.) Makino (GpM) (Jiaogulan) has been widely used in Chinese medicine for the treatment of various diseases, including hepatitis, diabetes and cardiovascular disease. Modern medical research has shown that GpM exhibits a variety of pharmacological properties, including anti-inflammatory [5-8], antioxidative [9-13], lipid metabolism regulatory [14-18], antiproliferative [19-22], neuroprotective [23,

*Correspondence: wzma@must.edu.mo

State Key Laboratory of Quality Research in Chinese Medicine, Macau

University of Science and Technology, Taipa, Macao, China
24] and anxiolytic activities [25-27]. GpM has consequently been widely used for the treatment of hepatitis [15, 28-30], diabetes [11, 30-32], cardiovascular disease [33-35] and cancer [20, 23, 36, 37]. GpM is also widely used as a health supplement in beverages, biscuits, noodles, face washes and bath oils [38-41].

We have conducted a comprehensive review of the literature associated with GpM to provide a summary of recent research towards the anti-cancer activities and mechanisms of action of GpM. We have also searched the PubMed, Web of Science and China National Knowledge Infrastructure (CNKI) databases to identify the material basis for the anti-cancer effects of GpM.

\section{Literature search strategy and exclusion criteria}

Our literature search covered all of the records in the PubMed, Web of Science Core Collection and CNKI databases up until the beginning of August, 2016. All of the studies included in this review reported on either the chemical components or the anti-cancer effects of GpM. The following search strategy was used to search PubMed 
with the "All Fields" option and the Web of Science Core Collection in the "Topic" field (Table 1). Studies were excluded if they were: (a) duplicated; (b) not pertinent to the chemical components or the anti-cancer effects of GpM; or (c) not full-text journal articles.

Clinical studies were not excluded from the searches conducted using the PubMed and Web of Science database; however, no records involving clinical trials were found in either of these databases. For this reason, we searched the CNKI database for clinical studies pertaining to the use of GpM for the treatment of cancer. The following search strategy was used to search the CNKI database using the "Abstract" field (Table 2). Studies were excluded from the results if they were: (a) not pertinent to the clinical anti-cancer effects of GpM; (b) review articles; or (c) not full-text journal articles.

Two reviewers independently searched the databases and screened all of the articles for their eligibility. The search strategies and selection processes used by the reviewers are shown in Fig. 1. In this way, we identified 108 articles, which have been included in this review.

\section{Chemical components of GpM}

Over 230 compounds have been identified as being derived from GpM and can be grouped according to their chemical structures into saponins, sterols, flavonoids, polysaccharides and several other compound classes.

\section{Saponins}

One hundred and eighty-nice saponins, which are also known as gypenosides (Gyps), have been isolated from

Table 1 Strategy in searching PubMed and Web of Science

\begin{tabular}{llrr}
\hline Step & Search terms & \multicolumn{2}{c}{ Citations reviewed } \\
\cline { 3 - 4 } & & PubMed & Web of Science \\
\hline 1 & Gynostemma pentaphyllum & 280 & 314 \\
2 & Jiaogulan & 284 & 22 \\
3 & Gypenoside & 137 & 96 \\
4 & Constituents & 58,058 & 137,552 \\
5 & Composition & 328,924 & 780,071 \\
6 & Components & 471,244 & $1,371,871$ \\
7 & Tumor & $3,285,652$ & 983,570 \\
8 & Cancer & $3,336,622$ & $1,467,455$ \\
9 & Carcinoma & 797,702 & 521,059 \\
10 & 1 or 2 or 3 & 322 & 364 \\
11 & 4 or 5 or 6 & 821,820 & $2,163,770$ \\
12 & 7 or 8 or 9 & $3,699,522$ & $2,049,723$ \\
13 & 10 and 11 & 66 & 109 \\
14 & 10 and 12 & 81 & 83 \\
15 & 13 or 14 & 130 & 162 \\
\hline & & &
\end{tabular}

Table 2 Strategy in searching CNKI

\begin{tabular}{llc}
\hline Step & Search terms & Citations reviewed \\
\hline 1 & Jiaogulan & 2876 \\
2 & Zhongliu & 767,939 \\
3 & Linchuang & $3,366,530$ \\
4 & 1,2 and 3 & 43 \\
\hline
\end{tabular}

GpM and fully characterized using spectroscopic methods [42-45]. At the 23rd meeting of the Japanese society of pharmacognosy, Nagai et al. [46] reported the isolation of two dammarane-type saponins, including panoxadiol and $2 \alpha-\mathrm{OH}$-panoxadiol, from the hydrolysate of Gyps. The research groups of Takemotoet [47-50] and Yoshikawa [51, 52] subsequently reported the isolation and characterization of many other Gyps from GpM. Gyps are the major components of GpM, and mainly consist of triterpenoid saponins, which can be purified from ethyl acetate or n-butanol extracts [53]. One hundred and sixty-five of the 189 Gyps reported to date have been grouped into 12 classes based on the nature of their aglycone moiety [43]. However, the remaining 24 Gyps [44, $45,54-60]$ do not belong to any of these classes. The general structure of Gyps is shown in Table 3, and shows that these compounds consist of a hydrophobic sapogenin moiety (where $\mathrm{R}_{1}=$ hydrocarbon chain with or without double bond(s), cyclopentane, oxacyclopentane or some other group) and a hydrophilic sugar group (where $\mathrm{R}_{4}=$ glucose, rhamnose or xylose).

\section{Sterols}

Sterols are composed of 17 carbon atoms across four rings, i.e., three 6-carbon rings and a single 5-carbon ring, with a side chain extending from $\mathrm{C} 17$ containing nine or ten carbon atoms (Additional file 1: Table S1). Eighteen sterols were isolated from $\mathrm{GpM}$ and fully characterized using a unique method from 1986 to 1990 [61-67]. Briefly, GpM was extracted with $\mathrm{CH}_{2} \mathrm{Cl}_{2}$, and the extracted lipids were saponified with $5 \% \mathrm{KOH}$ in $\mathrm{MeOH}$. After purification by column chromatography over silica gel, the sterol mixture was acetylated, crystallized and characterized using spectroscopic methods. This process resulted in the isolation of sterols with ergostane, cholestane and stigmastane skeletons. The structures of these 18 sterols are shown in Additional file 1: Table S1. These compounds contained one double bond between $\mathrm{C} 5-\mathrm{C} 6, \mathrm{C} 7-\mathrm{C} 8$ or $\mathrm{C} 9-\mathrm{C} 11$, with $\mathrm{R}_{2}=\mathrm{H}$ or $\mathrm{CH}_{3}$ and $\mathrm{R}_{1}=$ hydrocarbon chain with 10 carbons, and one double bond or one alkynyl group.

\section{Polysaccharides}

Polysaccharides are major components of GpM, where they are typically conjugated with proteins [68]. The 


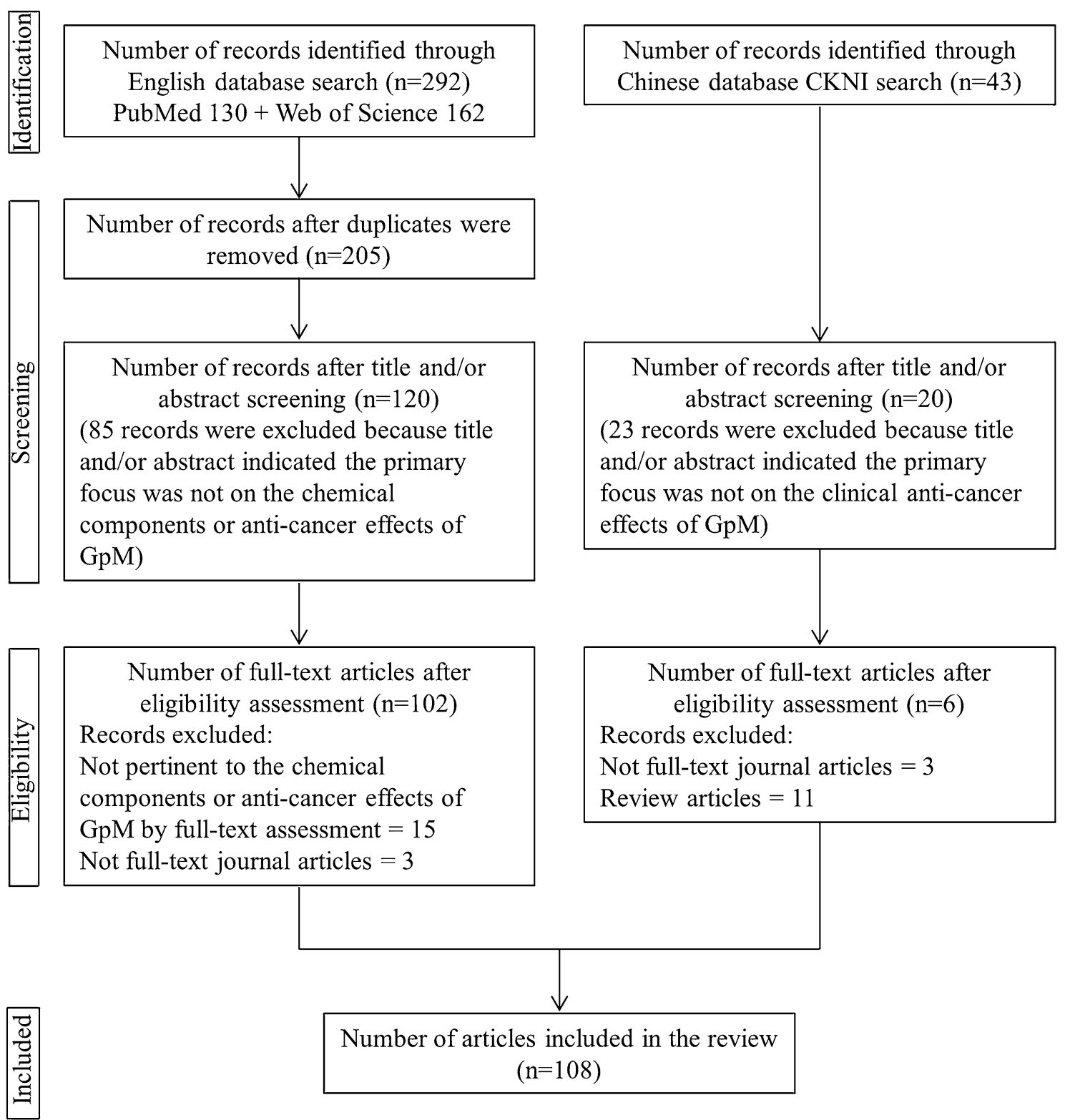

Fig. 1 Flowchart indicating the search strategies and processes used in this study

molecular weight of the polysaccharides found in GpM varies from 9000 to 33,000 Da [69]. Several different kinds of polysaccharides have been found in GpM, and the molar ratios of the monosaccharide components of these systems have been reported to vary considerably. For instance, the neutral polysaccharide fraction CGPP mainly consists of mannose, glucose, arabinose, rhamnose, galactose and glucuronic acid with molar ratios of 2.0:2.2:1.3:2.2:1.2:2.5 [20]. Another polysaccharide fraction $(\mathrm{NaCl}$ eluted fraction of crude polysaccharides from GpM by DEAE-Sepharose CL-6B chromatography, GMC) consisted of glucose, galactose, mannose and fructose with the molar ratios of 1:2.17:1.25:1.02 [70]. Furthermore, the water-soluble GpM polysaccharide fraction GP-I contains glucose, galactose, mannose, rhamnose and arabinose with molar ratios of 5.3:4.2:3.0:0.7:0.8 [69]. Based on the differences in the possible arrangements of the monosaccharides, various polysaccharides have been isolated from $\mathrm{GpM}$ [71]. 

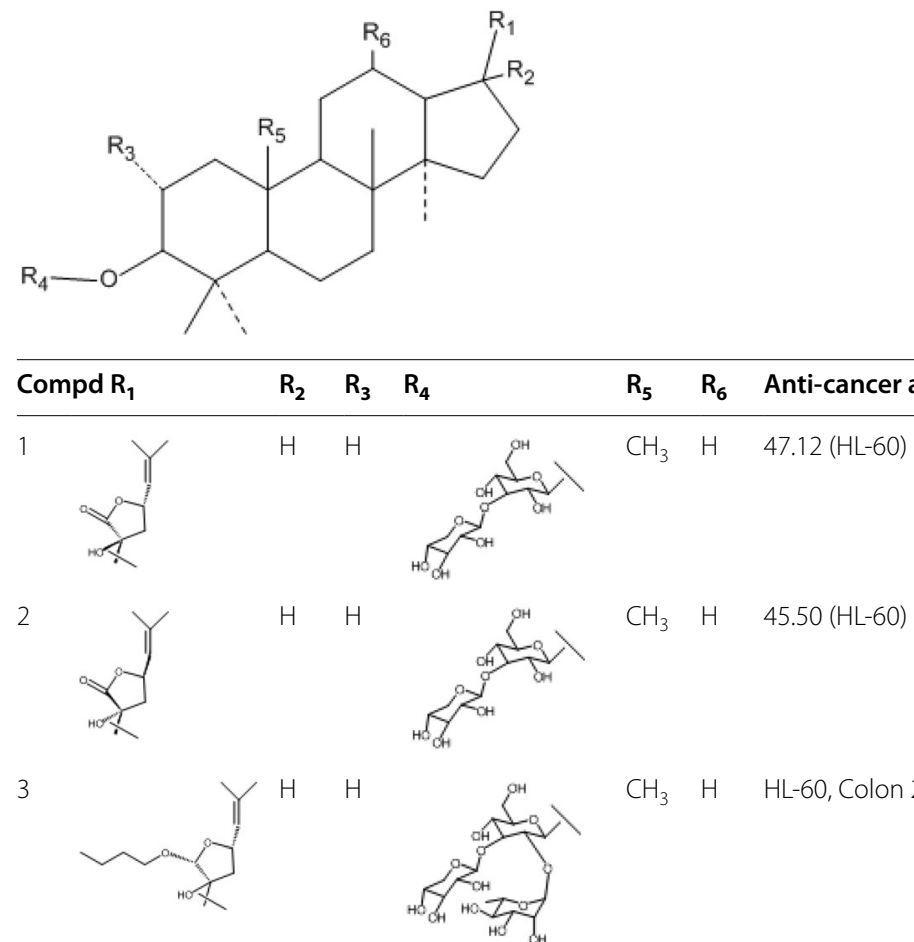

Reference

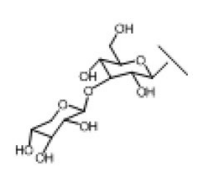

$\mathrm{CH}_{3} \quad \mathrm{H} \quad 45.50(\mathrm{HL}-60)$

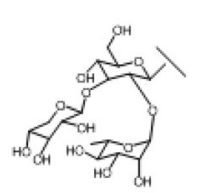

$\mathrm{CH}_{3} \quad \mathrm{H} \quad \mathrm{HL}-60$, Colon 205, Du145, GC-7901, BEL-7402

$[85,86]$

4<smiles>CCCCOC1CC(C=C(C)C)CC1(C)NC</smiles>

5<smiles>CCCCOC1CC(C)C(C)(C)C1C=C(C)C</smiles>

6<smiles>CCCCOC1OC(C=C(C)C)CC1(C)C</smiles>

7<smiles>CC(C)=CC1CC(O)C(C)(C)C1</smiles>

8<smiles>CC(C)=CC1CC(C)(C)C(O)O1</smiles>

9<smiles>CC(C)(C)C1CC(O)C(O)C1C(C)(C)C</smiles><smiles>CC12CC3CC(CC(C3)C1)C2</smiles>

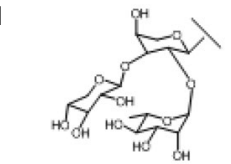

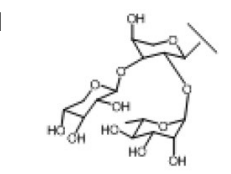

$\mathrm{CH}_{3} \mathrm{H}$

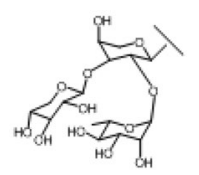

$\mathrm{CH}_{3} \mathrm{H}$

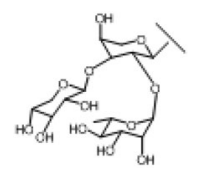

$\mathrm{CH}_{3} \mathrm{H}$

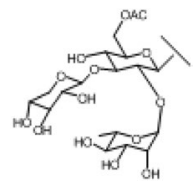

$\mathrm{CH}_{3} \quad \mathrm{H} \quad \mathrm{HL}-60$, Colon 205, Du145, GC-7901, BEL-7402

$[85,86]$

CHO H HL-60, Colon 205, Du145, GC-7901, BEL-7402

$[85,86]$

$[85,86]$

CHO H HL-60, Colon 205, Du145, GC-7901, BEL-7402

CHO H HL-60, Colon 205, Du145, GC-7901, BEL-7402

$[85,86]$

CHO H HL-60, Colon 205, Du145, GC-7901, BEL-7402

$[85,86]$

$\mathrm{CH}_{3} \quad \mathrm{H} \quad \mathrm{HL}-60$, Colon 205, Du145, GC-7901, BEL-7402

[122]

$22]$


Table 3 continued<smiles>[R]OC1C([R3])CC2([R5])C(CCC3(C)C2CC([R6])C2C([R2])([R2])CCC23I)C1(C)C</smiles>

\begin{tabular}{|c|c|c|c|c|c|c|c|}
\hline Compd $\mathrm{R}_{1}$ & $\mathbf{R}_{2}$ & $\mathbf{R}_{\mathbf{3}}$ & $\mathbf{R}_{4}$ & $\mathbf{R}_{\mathbf{5}}$ & $\mathrm{R}_{6}$ & Anti-cancer activity ${ }^{a}$ & Reference \\
\hline 10 & $\mathrm{CH}_{3}$ & $\mathrm{H}$ & & $\mathrm{CH}_{3}$ & $\mathrm{OH}$ & $\begin{array}{l}67.66 \pm 3.36(\mathrm{HL}-60), 18.45 \pm 0.93 \text { (MCF-7) } \\
34.95 \pm 0.93(\mathrm{HT}-29), 20.97 \pm 1.49 \text { (A549), } 27.68 \pm 1.58 \\
\text { (SK-OV-3) }\end{array}$ & [53] \\
\hline 11 & $\mathrm{CH}_{3}$ & $\mathrm{H}$ & & $\mathrm{CH}_{3}$ & $=0$ & $\begin{array}{l}>109.2 \text { (HL-60), } 42.81 \pm 3.60 \text { (MCF-7), } 22.06 \pm \\
\quad 2.18 \text { (HT-29), } 31.45 \pm 2.62 \text { (A549), } 30.25 \pm 1.53 \text { (SK-OV-3) }\end{array}$ & [53] \\
\hline 12 нор & $\mathrm{CH}_{3}$ & $\mathrm{H}$ & & $\mathrm{CH}_{3}$ & $=0$ & $\begin{array}{l}>107.6 \text { (HL-60), } 23.03 \pm 1.40 \text { (MCF-7), } 46.30 \pm \\
\quad 1.08 \text { (HT-29), 21.09 } \pm 1.18 \text { (A549), 35.62 } \pm 0.97 \text { (SK-OV-3) }\end{array}$ & [53] \\
\hline 13 & $\mathrm{CH}_{3}$ & $\mathrm{H}$ & & $\mathrm{CH}_{3}$ & $=0$ & $\begin{array}{l}76.63 \pm 2.98 \text { (HL-60), } 23.62 \pm 1.02 \text { (MCF-7), } \\
39.34 \pm 1.02 \text { (HT-29), } 19.90 \pm 1.40 \text { (A549), } 19.90 \pm \\
1.49 \text { (SK-OV-3) }\end{array}$ & [53] \\
\hline 14 & $\mathrm{H}$ & $\mathrm{H}$ & & $\mathrm{CH}_{3}$ & $\mathrm{H}$ & 7.44 (HL-60), 27.80 (Colon 205), 24.12 (Du145) & [127] \\
\hline 15 & $\mathrm{H}$ & $\mathrm{H}$ & $\mathrm{H}$ & $\mathrm{CH}_{3}$ & $\mathrm{H}$ & 3.90 (MDA-MB-435) & [128] \\
\hline 16 & $\mathrm{H}$ & $\mathrm{H}$ & $\mathrm{H}$ & $\mathrm{CH}_{3}$ & $\mathrm{H}$ & $0.05 \pm 0.01$ (A549), $0.25 \pm 0.07$ (U87) & [129] \\
\hline 17 & $\mathrm{H}$ & $\mathrm{OH}$ & $\mathrm{H}$ & $\mathrm{CH}_{3}$ & $\mathrm{OH}$ & $12.54 \pm 0.53(\mathrm{~A} 549)$ & [130] \\
\hline 18 & $\mathrm{H}$ & $\mathrm{OH}$ & & $\mathrm{CH}_{3}$ & $\mathrm{OH}$ & $34.94 \pm 4.23(\mathrm{~A} 549)$ & [130] \\
\hline 19 & $\mathrm{H}$ & $\mathrm{H}$ & $\mathrm{H}$ & $\mathrm{CH}_{3}$ & $\mathrm{H}$ & $40 \pm 0.7(\mathrm{HepG} 2)$ & [44] \\
\hline 20 & $\mathrm{H}$ & $\mathrm{H}$ & $\mathrm{H}$ & $\mathrm{CH}_{3}$ & $\mathrm{OH}$ & $38 \pm 0.5($ HepG2) & [44] \\
\hline
\end{tabular}


Table 3 continued
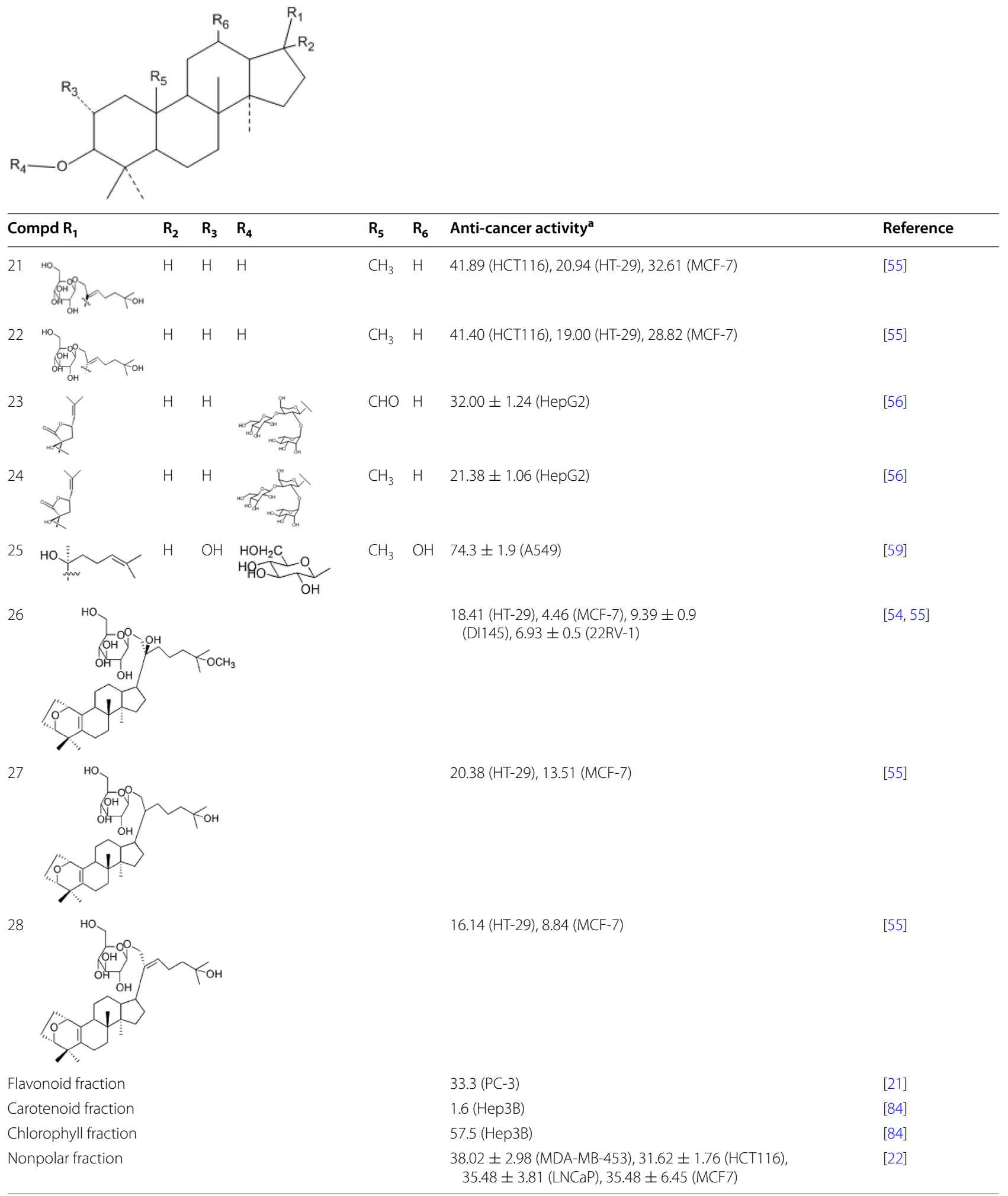


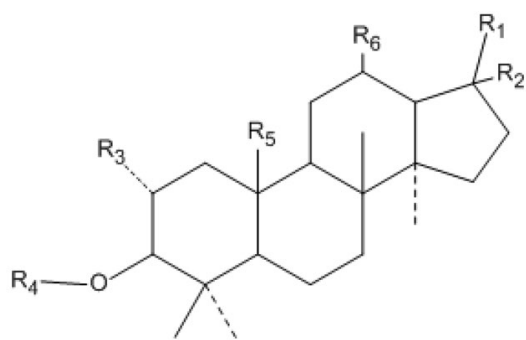

\begin{tabular}{|c|c|c|c|c|c|c|}
\hline Compd $\mathrm{R}_{\mathbf{1}}$ & $\begin{array}{ll}R_{2} & R_{3}\end{array}$ & $\mathbf{R}_{\mathbf{4}}$ & $\mathrm{R}_{\mathbf{5}}$ & $\mathrm{R}_{6}$ & Anti-cancer activity ${ }^{a}$ & Reference \\
\hline Gypenosides & & & & & $\begin{array}{l}\text { 47.6 (Hep3B), } 39.3 \text { (PC-3), } 30.6 \text { (A549) HL-60, MCF-7, } \\
\text { HT-29, Colon 205, Du145, MDA-MB-435, U87, A549, } \\
\text { SK-OV-3, HepG2, SGC-7901, BEL-7402, Huh-7, HA22T, } \\
\text { SW620, Eca-109, SAS, L1210, WEHI-3, SW-480, KB/NCR, } \\
\text { MCF-7/ADR }\end{array}$ & $\begin{array}{l}{[19,21,36,44} \\
85-87,89-91 \\
105-109,111 \\
112,114,115 \\
119,121,131 \\
132]\end{array}$ \\
\hline Polysaccharide & & & & & 65.4 (B16), HT-29, B16, Hela, SW-1116, HepG2 & {$[44,87,88,119]$} \\
\hline Ethanolic extract & & & & & $\mathrm{C} 6, \mathrm{HT}-59$ & {$[113,133]$} \\
\hline
\end{tabular}

a The anti-cancer activities, $\mathrm{IC}_{50}(\mu \mathrm{g} / \mathrm{ml})$, of components of $\mathrm{GpM}$ are expressed as mean \pm SD following cell line names in bracket. Only the mean value is listed if there is no SD value available and only cancer cell line name is listed if no IC ${ }_{50}$ data is available. The unit of compound 10,11,12, 13, 16, 21,22, 26, 27 and 28 are transformed based on molecular weight. This table also presents 30 cancer cell lines whose proliferation could be inhibited by $\mathrm{GpM}$, which indicates that GpM exerts broad spectrum anti-cancer activities

\section{Flavonoids}

Flavonoids are an important class of polyphenol compounds that are widely distributed in fruits and vegetables, where they usually exist in their glycosidic form [72]. In terms of their general structure, flavonoids consist of a 15-carbon skeleton, containing two phenyl rings (A and B) and a heterocyclic ring $(\mathrm{C})$. The carbon structure of these compounds is usually abbreviated as C6C3-C6. Several flavonoids have been isolated from GpM, including quercetin, rutin, ombuoside [73], ombuin [74], isorhamnetin-3-O-rutinoside, isorhamnetin [75], quercetin-di-(rhamno)-hexoside, quercetin-rhamno-hexoside, kaempferol-rhamno-hexoside and kaempferol-3-O-rutinoside [76], and the structures of these flavonoids are shown in Additional file 1: Table S2.

\section{Other components of GpM}

$\mathrm{GpM}$ contains various trace elements (e.g., $\mathrm{Cu}, \mathrm{Fe}, \mathrm{Zn}$, Mn, Co, Ni, Se, Mo and Sr) [77], 18 amino acids [78] (including eight essential amino acids) and various vitamins and proteins, but the relative amounts of these components vary considerably across the different parts of the GpM plant (i.e., leaf, stem and subterranean stem) [78]. Malonic acid [74], benzyl-O- $\beta$-D-glucopyranoside [79], lutein, vomifoliol, palmitic acid [80], linolenic acids [81, 82] and carrot glycosides [83] have also been isolated from GpM. Furthermore, Tsai et al. [84] reported the isolation of numerous carotenoids and chlorophylls from the carotenoid and chlorophyll fractions of GpM, respectively.

\section{Anti-cancer activities of GpM In vitro anti-cancer activities of GpM}

The in vitro antiproliferative activities of some of the pure compounds and extracts isolated from GpM have been widely reported and the details of these materials are summarized in Table 3. Shi et al. [85] obtained four dammarane-type triterpene saponins (compounds 3-6) from the aerial parts of GpM, which exhibited moderate cytotoxic activities in vitro against several human cancer cell lines, including HL-60 (human promyelocytic leukemia cells), Colon 205 (human colon cancer cells) and Du145 (human prostate carcinoma cells) cells. Yin et al. [86] isolated nine dammarane saponins from the methanol extract of the aerial part of GpM, and found that compounds 7, 8 and 9 exhibited inhibitory activities towards the growth of SGC-7901 (stomach cancer cells) and BEL74020 (hepatocellular carcinoma cells) at a concentration of $100 \mu \mathrm{M}$ with percentage inhibition values of 21,93 and $8 \%$, and 77,92 and $40 \%$, respectively.

Almost all of the compounds and extracts isolated from GpM to date have be reported to exhibit noticeable antiproliferative activities with $\mathrm{IC}_{50}$ values ranging from 0.05 to $74.3 \mu \mathrm{g} / \mathrm{mL}$ (Table 3). Compound 16 exhibited potent antiproliferative activities against A549 human lung cancer cells and U87 glioblastoma cells with $\mathrm{IC}_{50}$ values of 0.05 and $0.25 \mu \mathrm{g} / \mathrm{mL}$, respectively. Compound 15 showed antiproliferative activity against MDA-MB-435 human breast cancer cells with an $\mathrm{IC}_{50}$ value of $3.90 \mu \mathrm{g} / \mathrm{mL}$, whereas the carotenoid fraction of GpM exhibited the strongest activities of all of the reported extracts with an 
$\mathrm{IC}_{50}$ value of $1.6 \mu \mathrm{g} / \mathrm{mL}$ against Hep3B human hepatocellular carcinoma cells.

The hydrolysates of the extracts of GpM have also been reported to exhibit anti-cancer activities, together with several other derivatives of the natural products found in GpM. For example, Chen et al. [87] reported the synthesis of four sulfated derivatives of GPP2, which is a native polysaccharide isolated from GpM. One of the sulfated derivatives prepared by Chen (GPP2-s4) inhibited the growth of HepG2 human hepatocellular carcinoma cells by $46.4 \pm 2.8 \%$ at a concentration of $2000 \mu \mathrm{g} / \mathrm{mL}$. Compared with GPP2, all four sulfated derivatives exhibited stronger antiproliferative activities against $\mathrm{HeLa}$ cervical cancer cells at concentrations as low as $100 \mu \mathrm{g} / \mathrm{mL}$. GP-B1, which is an acidic polysaccharide derived from GpM, significantly inhibited the growth of B16 melanoma cells with an $\mathrm{IC}_{50}$ of $65.4 \mu \mathrm{g} / \mathrm{mL}$ with very little cytotoxicity against normal cells [88]. Moreover, GP-B1 not only significantly inhibited the growth of cancer cells, but also improved cellular immune response by increasing levels of tumor necrosis factor- $\alpha$ (TNF- $\alpha$ ), interferon- $\gamma$ (IFN- $\gamma$ ), interleukin-10 (IL-10) and interleukin-12 (IL-12) observed in the serum of melanomaB16-bearing mice [88].

\section{In vivo anti-cancer activities of GpM}

The in vivo anti-cancer activities of $\mathrm{GpM}$ are summarized in Table 4. Gyps led to significant reductions in the size of solid tumors in nude mice injected with SAS oral cancer cells [89]. Gyps also promoted the survival of mice xenografted with WEHI-3 leukemia cells, which was accompanied by an increase in the number of megakaryocytes and reduced spleen weight in these animals, indicating an enhanced immune response [90]. Similar anti-cancer activities have also been reported for Gyps in another leukemia mouse model [91]. The intraperitoneal treatment of tumor-bearing mice with Gyps ( 5 or $20 \mathrm{mg} / \mathrm{kg} /$ day) for 4 weeks led to considerable decreases in the size and weight of their tumors without altering their body weight. Gyps also strongly suppressed tumor growth in mice bearing advanced S180 sarcoma, which was associated with an increase in the ratio of tumor necrosis area to tumor total area and lymphocyte/macrophage infiltration into the peripheral areas of tumors. This effect also led to an increase in the weight of the spleens of these animals, as well as increases in the quantity and size of their splenic white pulp [92]. Gyps enhanced the anti-cancer effects of 5-fluorouracil in colorectal cancer cells and xenografts [93]. Gyps have also been reported to inhibit tumorigenesis in a transgenic mouse models of cancer, such as the $\mathrm{Apc}^{\mathrm{Min} /+}$ mouse model of intestinal neoplasia [94, 95]. Moreover, rats fed with a standardized extract of GpM did not show any mortal or toxic effects, highlighting the good safety profile of this material [96].

A polysaccharide from GpM inhibited the development of transplanted S180 sarcoma in a dose-dependent manner and increased the phagocytosis of macrophages, as well as increasing the production of NO, IL-1 $\beta$ and TNF- $\alpha$ from the peritoneal macrophages [97]. The neutral polysaccharide fraction CGPP inhibited the growth of $\mathrm{H} 22$ hepatocarcinoma cells transplanted into ICR mice [20]. CGPP treatment also led to improvements in the body weight, spleen/thymus index and degree of splenocyte proliferation in tumor-bearing mice [20]. Furthermore, CGPP treatment led to considerable increases in the levels of cytokines, such as IL-2, TNF- $\alpha$ and IFN- $\gamma$ in tumor-bearing mice, as well as increases in the activity of natural killer (NK) cells and cytotoxic T lymphocytes (CTL) [20]. The tumor inhibitory and immunoregulatory effects of CGPP greatly increased the life span of H22 ascites in tumor-bearing mice [20].

\section{Clinical anti-cancer studies on GpM}

A clinical study was conducted in 1993 involving 59 patients with advanced malignant tumors to assess the effects of GpM [98]. The results revealed that patient treated with a GpM formula showed cancer relapse and metastasis rates of 11.9 and $8.5 \%$, respectively, compared with values of 72.4 and $55.2 \%$ in the control group. The results of this study also revealed that the $\mathrm{T}$ lymphocyte transformation rate and acid $\alpha$-naphthyl acetate esterase (ANAE+) activity increased by $8.2 \%$ following GpM treatment [98]. The results of a separate 5-year observational study also showed that the treatment of cancer patients with GpM formula led to significant reductions in cancer relapse and metastasis rates, as well as reduced mortality and improved immune function in these patients [99]. GpM has also been reported to enhance NK cell activity in breast cancer patients [100], and improve the immune function of cancer patients after chemotherapy, as demonstrated by increased $\mathrm{T}$ lymphocyte transformation rate and decreased IgG and IgM levels [101]. Furthermore, GpM enhanced the immunological function of lung cancer patients after chemotherapy [102]. The results of a recent study [103] demonstrated that GpM formula can work in synergy with chemotherapy reagents. The clinical uses of GpM are summarized in Table 5.

\section{Mechanisms of action}

Multiple mechanisms of action have been proposed regarding the anti-cancer activities of $\mathrm{GpM}$, including cell cycle arrest, apoptosis induction, inhibition of invasion and metastasis, glycolysis inhibition and immunomodulation (Fig. 2). 


\section{Cell cycle arrest}

Gyps induced cell cycle arrest at the G0/G1 phase SAS human oral cancer cells [89], WEHI-3 leukemia cells [90], A549 human lung adenocarcinoma cells [104], HL-60 human myeloid leukemia cells [91] and Colo 205 human colon cancer cells [105]. Gyps also induced cell cycle arrest by modulating the expression of several cell cycle regulatory proteins, including cyclin-dependent kinase 2 (CDK2), cyclin-dependent kinase 4 (CDK4) and cyclin-dependent kinase 6 (CDK6) $[21,106]$. The treatment of SCC-4 human tongue cancer cells with Gyps induced checkpoint kinase 2 (Chk2) expression. This effect subsequently led to the upregulation of p53 and its targets p21 and p16, which led to decreased levels of cyclin D and cyclin E and G0/G1 cell cycle arrest [106]. The treatment of PC-3 human prostate carcinoma cells with flavonoids and saponins isolated from GpM led to cell cycle arrest in the $S$ and G2/M phases in both cases by modulating the expression of cyclins [21]. Furthermore, A549 cells treated with flavonoids from GpM went into cell cycle arrest in the $S$ and G2/M phases, and showed upregulated levels of Cyclin A, Cyclin B, p21 and p53 [24].

\section{Induction of apoptosis}

A large number of studies have shown that GpM exerts its anti-cancer activities by inducing cellular apoptosis through various signaling pathways. Gyps downregulated the anti-apoptotic proteins $\mathrm{Bcl}-2$ and $\mathrm{Bcl}-\mathrm{xL}$, and upregulated the pro-apoptotic proteins Bax, Bad and Bak, thereby activating the formation of $\mathrm{Bax} / \mathrm{Bak}$ pores on the outer mitochondrial membrane [89-91, 107, 108]. Bax/ Bak pores allow for the release of cytochrome $\mathrm{c}$ and other pro-apoptotic proteins into the cytosol, leading to the activation of initiator caspases- 8 and -9 , followed by the cleavage of effector caspase-3, which ultimately triggers apoptosis [104-106]. The formation of Bax/Bak pores following Gyps treatment also led to the release of apoptosis inducing factor (AIF) and endonuclease G (EndoG) from the mitochondria [89, 106], following DNA fragmentation and chromatin condensation.

Gyps also induced the production of reactive oxygen species (ROS) [36, 89, 105, 106, 108, 109] and led to increased intracellular $\mathrm{Ca}^{2+}$ concentrations [89-91, $105,106,108]$. ROS and $\mathrm{Ca}^{2+}$ are both well-studied modulators of the permeability transition pores located on the inner mitochondrial membrane. The opening of these pores leads to an influx of solutes and water into the mitochondrial matrix, causing the outer mitochondrial matrix to swell and rupture, which leads to the release of cytochrome c and apoptosis [89-91, 105-107]. Gyps treatment led to increased levels of
DNA-damage-inducible transcript 3 (GADD153), glucose-regulated protein (GRP78), activating transcription factor 6 alpha (ATF6- $\alpha$ ) and activating transcription factor 4 alpha (ATF4- $\alpha$ ). These increases resulted in endoplasmic reticulum (ER) stress, which could result in the release of $\mathrm{Ca}^{2+}$ from the ER [89-91, 106]. Moreover, Sun et al. [110] reported increased store-operated $\mathrm{Ca}^{2+}$ entry as another mechanism of action for the activity of Gyps.

Furthermore, Gyps induced dose-dependent DNA damage in SAS cells and reduced the expression of several DNA repair genes, including ataxia telangiectasia mutated, ataxia-telangiectasia and Rad3-related, breast cancer gene 1, 14-3-36, DNA-dependent serine/threonine protein kinase and p53, in a time-dependent manner. In this way, Gyps treatment stalled the DNA damage repair process, forcing the cells to undergo apoptosis $[109,111]$.

Several other components and fractions of GpM have also been reported to induce apoptosis. For instance, flavonoids [21] and a water extract [112] from GpM induced apoptosis in tumor cells via the regulation of the Bcl-2 protein family. Furthermore, an ethanolic extract from GpM selectively shifted the intracellular $\mathrm{H}_{2} \mathrm{O}_{2}$ concentration to toxic levels in tumor cells because of the increased superoxide dismutase activity of these cells compared with healthy cells [113].

\section{Inhibition of invasion and metastasis}

Gyps suppressed the invasion and migration of SCC4 human tongue cancer cells in a dose- and time-dependent manner by downregulating nuclear factor kappa $\mathrm{B}$ (NF- $\mathrm{kB}$ ) and matrix metalloproteinase-9 (MMP-9) [114]. Gyps also inhibited the invasion and migration of SAS cells, as demonstrated by the results of in vitro wound-healing and Boyden Chamber assays. Treatment with Gyps led to decreases in the levels of several migration- and invasion-associated proteins, including NF- $\mathrm{KB}$, cyclooxygenase-2, extracellular signal-regulated kinase 1/2 (ERK1/2), matrix metalloproteinase-2 (MMP-2), MMP-9, sevenless homolog, Ras, urokinase-type plasminogen activator, focal adhesion kinase and alpha serine/threonine protein kinase [115]. Furthermore, Gyps exhibited anti-migration activities towards SW620 human colon adenocarcinoma cells and Eca-109 human esophageal squamous carcinoma cells [19]. Gyps also inhibited the migration of SW-480 human colon adenocarcinoma cells in vitro at a concentration of $100 \mu \mathrm{g} /$ $\mathrm{mL}$ [36]. This effect was observed in clinical studies. For example, patients with advanced malignant tumors that were treated with GpM formula showed a reduced cancer metastasis rate of $8.5 \%$ compared with $55.2 \%$ in the control group [36]. 
Table 4 In vivo anti-cancer activity of identified GpM components

\begin{tabular}{|c|c|c|c|}
\hline Component & Animal model & Anti-cancer activity ${ }^{a}$ & Reference \\
\hline Gypenosides & Nude mice: xenografted with human oral cancer SAS cells & $65.76 \%$ (tumor size, 20 mg/kg for 28 days) & [89] \\
\hline Gypenosides & BALB/c mice: injected with human leukemia WEHI-3 cells & $\begin{array}{l}150 \% \text { (survival rate, } 2 \text { mg/kg for } 2 \text { weeks) } \\
175 \% \text { (survival rate, } 4 \text { mg/kg for } 2 \text { weeks) }\end{array}$ & {$[90]$} \\
\hline Gypenosides & Nude mice: xenografted with human leukemia HL-60 cells & 44 \% (tumor size, 20 mg/kg for 28 days) & {$[91]$} \\
\hline Gypenosides & BALB/c mice: xenografted with murine $\mathrm{S} 180$ sarcoma cells & 39.57 \% (tumor size, 30 mg/kg for 4 days) & {$[92]$} \\
\hline Gypenosides & $\begin{array}{l}\text { BALB/c mice: xenografted with murine colorectal cancer CT-26 } \\
\text { cells }\end{array}$ & $\begin{array}{l}75 \% \text { (tumor size, } 25 \mathrm{mg} / \mathrm{kg} \text { for } 19 \text { days) } \\
55 \% \text { (tumor size, } 50 \mathrm{mg} / \mathrm{kg} \text { for } 19 \text { days) } \\
26 \% \text { (tumor size, } 50 \mathrm{mg} / \mathrm{kg}+5 \mathrm{mg} / \mathrm{kg} \text {-Fu for } 19 \text { days) }\end{array}$ & {$[93]$} \\
\hline Gypenosides & Apc $C^{\mathrm{Min} /+}$ mice: intestinal neoplasia model & $\begin{array}{l}66.06 \% \text { (polyps number, } 500 \text { mg/kg for } 4 \text { weeks) } \\
59.92 \% \text { (polyps number, } 750 \text { mg/kg for } 4 \text { weeks) }\end{array}$ & [94] \\
\hline Gypenosides & $A p C^{\mathrm{Min} /+}$ mice: intestinal neoplasia model & $59.32 \%$ (polyps number, 500 mg/kg for 8 weeks) & [95] \\
\hline Polysaccharide & BALB/c mice: xenografted with murine $\mathrm{S} 180$ sarcoma cells & $\begin{array}{l}62.77 \% \text { (tumor size, } 100 \mathrm{mg} / \mathrm{kg} \text { for } 14 \text { days) } \\
59.24 \% \text { (tumor size, } 200 \mathrm{mg} / \mathrm{kg} \text { for } 14 \text { days) }\end{array}$ & {$[97]$} \\
\hline Polysaccharide & ICR mice: xenografted with mouse hepatoma H22 cells & $\begin{array}{l}62.89 \% \text { (tumor size, } 50 \text { mg/kg for } 10 \text { days) } \\
49.22 \% \text { (tumor size, } 200 \text { mg/kg for } 10 \text { days) }\end{array}$ & {$[20]$} \\
\hline
\end{tabular}

a The anti-cancer activities of components of $\mathrm{GpM}$ are expressed as the percentage of control (readout, dose)

\section{Glycolysis inhibition}

One of the hallmarks of cancer cells is deregulated energy metabolism, which can lead to a state known as "aerobic glycolysis" [116]. Targeting glucose metabolism has therefore proven to be a promising avenue for the development of new cancer treatments [117]. GpMix, which is a mixture of triterpenoid saponins from GpM, effectively inhibited the growth of cancer cells in the presence of co-cultivated normal cells [118]. Furthermore, GpMix exhibited both chemopreventive and therapeutic effects towards the formation of intestinal polyps in Apc$\mathrm{min} /+$ mice (a mouse model of colon cancer). Several key enzymes along the glycolysis pathway, including pyruvate kinase (PK), $\alpha$-enolase, glyceraldehyde 3-phosphate dehydrogenase (GAPDH), mitochondrial aconitase and ATP synthase- $\alpha$ and $-\beta$ were found to be downregulated in R6 cells treated with GpMix by proteomic analysis [118]. These findings therefore implied that the inhibition of the glycolysis pathway was involved in the suppression of cell proliferation by GpMix.

\section{Immune modulation}

GpM also exhibited anti-cancer effects indirectly through its immunomodulating activities. For example, Yang et al. [119] found that a water-soluble polysaccharide from $G$. pentaphyllum herb tea (PSGP) indirectly exerted anticancer activity against SW-1116 human colorectal adenocarcinoma cells and HT-29 by enhancing the immune response of macrophages with increased TNF- $\alpha$ secretion in a dose-dependent manner. Moreover, GP-B1, the acidic polysaccharide obtained from GpM, not only significantly inhibited the growth of cancer cells, but also improved cellular immune response with increased levels of TNF- $\alpha$, IFN- $\gamma$, IL-10 and IL-12 in the serum of melanoma-B16-bearing mice [88]. The anti-cancer activity of Gyps was attributed to the elevated immune systems of the xenografted mice [120]. Gyps significantly suppressed tumor growth in mice transplanted with Lewis lung cancer cells with tumor weight inhibition rates of $29.8 \pm 1.3$, $51.4 \pm 2.2$ and $50.0 \pm 1.6 \%$ following intraperitoneal Gyps injections of 10,20 and $40 \mathrm{mg} / \mathrm{kg}$, respectively. Notably, the immune responses of these mice improved considerably, as demonstrated by increases in their total splenic cell number and the enhanced biological activities of the NK and splenic cells [120]. Clinical studies have also shown that GpM enhanced the activity of NK cells in breast cancer patients [100], improved the immune function of cancer patients after chemotherapy, increased the $\mathrm{T}$ lymphocyte transformation rate and decreased the IgG and IgM levels [101].

\section{Perspectives}

Numerous studies have been published during the last four decades regarding the anti-cancer effects of GpM, including reports focused on (i) the isolation and characterization of its chemical components [121, 122]; (ii) the evaluation of its anti-cancer activities and mechanisms of action [107, 115]; and (iii) studies on its toxicity [96]. Taken together, the results of these reports have demonstrated that GpM has a broad anti-cancer spectrum (against 30 cancer cell lines, Table 3) without any obvious inhibitory effect on normal cell proliferation. However, there are limitations associated with most of these studies. 
Table 5 Clinical uses of GpM

\begin{tabular}{lll}
\hline Component & Patient tumor type & Anti-cancer activity \\
\hline GpM formula & Multiple types & $16.44 \%$ (relapse rate) \\
& & $15.40 \%$ (metastasis rate) \\
GpM formula & Multiple types & $14.23 \%$ (relapse and metastasis rate) \\
GpM formula & Breast cancer & $129.56 \%$ (NK cell activity) \\
GpM formula & Multiple types & $157 \%$ (T lymphocyte transformation rate) \\
& & $78.4 \%$ (lgG levels) \\
& & $75.1 \%$ (lgA levels) \\
GpM formula & $59.9 \%$ (lgM levels) \\
GpM formula & Lung cancer & $128 \%$ (curative rate) \\
& Middle-late gastric cancer & $163 \%$ (short term curative rate)
\end{tabular}

a The anti-cancer activities of components of GpM are expressed as the percentage of control (readout)

\section{The standard preparation of Gyps needs to be unified} Gyps consist of a mixture of approximately 189 dammarane-type saponin glycosides. Most of the studies reported to date on GpM have focused exclusively on the use of its fractions, such as Gyps, as well as the use of its extracts. In contrast, there have been very few reports pertaining to the use of single compounds isolated from GpM. For example, in all of the papers published during the last 15 years regarding the anti-cancer mechanisms of GpM there has only been one study involving the use of single compounds. Based on to the lack of chemical consistency in the fractions and extracts of GpM, greater efforts should be taken to explore the anticancer activities of single compounds derived from GpM in future studies, where possible. Moreover, none of the Gyps tested in any of the studies reported to date were prepared using a unified procedure, which could have led to completely different chemical component profiles amongst the different samples. Most of these studies also failed to provide essential chemical composition information for their Gyps, such as the exact molecular structure of each saponin, the number of saponins in the mixture, the relative contents of the different saponins in Gyps and a standard HPLC fingerprint [19, 89, 90, 106, $107,109,111,115]$. Studies on the chemical structures of the saponins in Gyps are therefore urgently needed, as well as further studies towards the chemical composition and the quantitative analysis of Gyps. These data would allow researchers to develop a deeper understanding of the anti-cancer activities and mechanisms of action of Gyps and facilitate further studies.

\section{Experimental systems need to be closer to the clinical settings}

Most of the studies reported to date concerning the anti-cancer activities and mechanisms of action of GpM have been conducted using in vitro cellular systems. This trend could therefore explain why non-specific cell cycle arrest and the induction of apoptosis have been cited, in the majority of cases, as the principal mechanisms of action of GpM [89, 104, 106], with very few reports citing specific molecular targets or enzymatic pathways. In contrast, most of the in vivo studies conducted on GpM, have focused on the use of cancer cell lines implanted into immunodeficient mice [20, 90, 91]. According to this model, cancer cell lines are selected to survive in culture, and tumor-resident cells and proteins that interact with the cancer cells are eliminated to give a phenotypically homogeneous culture [123]. Patient-derived tumor xenograft (PDTX) models have several advantages over cell line xenograft models, such as maintaining the heterogeneity of the tumor and mimicking the microenvironment of human tumors [124]. Humanized-xenograft models can also be created by co-engrafting a sample of a patient-derived tumor together with peripheral blood or bone marrow cells into an immunodeficient mouse, followed by the reconstitution of the murine immune system. Advanced tumor models of this type can be used to study the interactions between xenogenic human stroma and tumor environments in cancer progression and metastasis [125]. Genetically engineered mouse models represent an interesting alternative for evaluating the effects of anti-cancer agents because these animals maintain a competent immune system, allowing for changes in the tumor microenvironment and the tumor itself to be thoroughly evaluated from an early stage [126]. Based on our review of the literature, we believe that further experiments should be performed in a PDTX, humanized-xenograft or genetically engineered mouse model to evaluate the effects of GpM on tumor development with greater clinical accuracy. The latter of these two models would be especially interesting in terms of evaluating the potential immunomodulatory activity of GpM. 


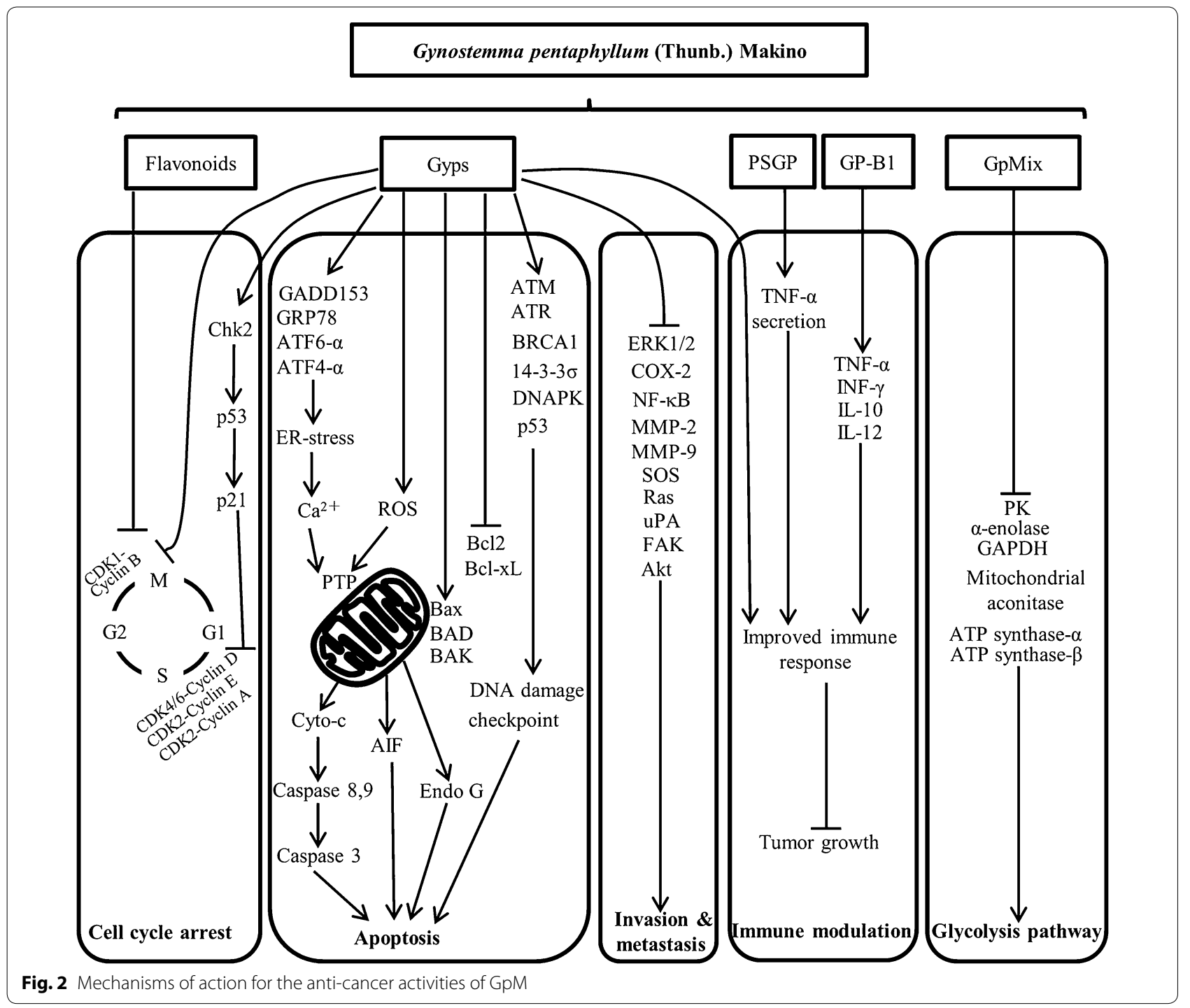

\section{Conclusion}

In summary, GpM has been investigated extensively as a potent anti-cancer agent against many types of cancers both in vitro and in vivo. The general consensus from the literature is that $\mathrm{GpM}$ exerts its anti-cancer activities through multiple mechanisms, including cell cycle arrest, the induction of apoptosis, inhibition of invasion and metastasis, glycolysis inhibition and immunomodulation.

\section{Additional file}

Additional file 1. Additional tables.

\section{Abbreviations}

AIF: apoptosis inducing factor; Akt: alpha serine/threonine protein kinase; ANAE+: acid a-naphthyl acetate esterase; ATF4-a: activating transcription factor 4 alpha; ATF6-a: activating transcription factor 6 alpha; ATM: ataxia telangiectasia mutated; ATR: ataxia-telangiectasia and Rad3-related; CDK2: cyclin-dependent kinase 2; CDK4: cyclin-dependent kinase 4; CDK6: cyclindependent kinase 6; Chk2: checkpoint kinase 2; CM: Chinese medicine; COX-2: cyclooxygenase-2; DNAPK: DNA-dependent serine/threonine protein kinase; EndoG: endonuclease G; ER: endoplasmic reticulum; ERK1/2: extracellular signal-regulated kinase 1/2; FAK: focal adhesion kinase; GADD153: growth arrest and DNA damage-inducible gene 153; GpM: Gynostemma pentaphyllum (Thunb.) Makino; GAPDH: glyceraldehydes 3-phosphate dehydrogenase; GRP78: glucose-regulated protein 78; Gyps: gypenosides; IFN- $\gamma$ : interferon- $\gamma$; IL-10: interleukin-10; IL-12: interleukin-12; MMP-2: matrix metalloproteinase-2; MMP-9: matrix metalloproteinase-9; NF-kB: nuclear factor kappa B; NK: natural killer; CTL: cytotoxic T lymphocytes; PK: pyruvate kinase; SOD: superoxide dismutase; SOS: sevenless homolog; TNA: tumor necrosis area; TNF-a: tumor necrosis factor-a; TTA: tumor total area; UPA: urokinase-type plasminogen activator.

\section{Authors' contributions}

$Y L, W L, J H, X Y$ and $W M$ conceived and designed the review. $Y L, W L, J H, X Y$ and WM wrote the manuscript. All authors read and approved the final manuscript. 


\section{Acknowledgements}

This work was supported by Grants from the Science and Technology Development Fund (FDCT) of Macau (Project codes: 034/2015/A1 and 088/2012/ A3).

\section{Competing interests}

The authors declare that they have no competing interests.

Received: 30 January 2015 Accepted: 19 September 2016 Published online: 27 September 2016

\section{References}

1. Cancer IARC. World cancer report 2014. Geneva: World Health Organization; 2014.

2. Carter GT. Natural products and pharma 2011: Strategic changes spur new opportunities. Nat Prod Rep. 2011;28:1783-9.

3. Pezzuto JM. Plant-derived anticancer agents. Biochem Pharmacol. 1997:53:121-33.

4. Lilenbaum RC, Green MR. Novel chemotherapeutic agents in the treatment of non-small-cell lung cancer. J Clin Oncol. 1993;11:1391-402.

5. Quan Y, Qian M. Effect and mechanism of gypenoside on the inflammatory molecular expression in high-fat induced atherosclerosis rats. Zhongguo Zhong Xi Yi Jie He Za Zhi. 2010;30:403-6.

6. Cai H, Liang Q, Ge G. Gypenoside attenuates beta amyloid-induced inflammation in n9 microglial cells via SOCS1 signaling. Neural Plast. 2016;2016:6362707.

7. Liou CJ, Huang WC, Kuo ML, Yang RC, Shen JJ. Long-term oral administration of Gynostemma pentaphyllum extract attenuates airway inflammation and Th2 cell activities in ovalbumin-sensitized mice. Food Chem Toxicol. 2010;48:2592-8.

8. Yang F, Shi H, Zhang X, Yang H, Zhou Q, Yu LL. Two new saponins from tetraploid jiaogulan (Gynostemma pentaphyllum), and their anti-inflammatory and a-glucosidase inhibitory activities. Food Chem. 2013:141:3606-13.

9. Zhao J, Ming Y, Wan Q, Ye S, Xie S, Zhu Y, Wang Y, Zhong Z, Li L, Ye Q. Gypenoside attenuates hepatic ischemia/reperfusion injury in mice via anti-oxidative and anti-apoptotic bioactivities. Exp Ther Med. 2014;7:1388-92

10. Yu H, Guan Q, Guo L, Zhang H, Pang X, Cheng Y, Zhang X, Sun Y. Gypenosides alleviate myocardial ischemia-reperfusion injury via attenuation of oxidative stress and preservation of mitochondrial function in rat heart. Cell Stress Chaperones. 2016;21:429-37.

11. Gao D, Zhao M, Qi X, Liu Y, Li N, Liu Z, Bian Y. Hypoglycemic effect of Gynostemma pentaphyllum saponins by enhancing the nrf2 signaling pathway in stz-inducing diabetic rats. Arch Pharm Res. 2016;39:221-30.

12. Schild L, Cotte T, Keilhoff G, Brodemann R. Preconditioning of brain slices against hypoxia induced injury by a Gynostemma pentaphyllum extract-stimulation of anti-oxidative enzyme expression. Phytomedicine. 2012;19:812-8.

13. Li $B$, Zhang $X Y$, Wang MZ, Jiao LL. Characterization and antioxidant activities of acidic polysaccharides from Gynostemma pentaphyllum (Thunb.) Markino. Carbohydr Polym. 2015;127:209-14.

14. la Cour B, Molgaard P, Yi Z. Traditional chinese medicine in treatment of hyperlipidaemia. J Ethnopharmacol. 1995:46:125-9.

15. Gou SH, Huang HF, Chen XY, Liu J, He M, Ma YY, Zhao XN, Zhang Y, Ni JM. Lipid-lowering, hepatoprotective, and atheroprotective effects of the mixture Hong-Qu and gypenosides in hyperlipidemia with NAFLD rats. J Chin Med Assoc. 2016:79:111-21.

16. Wang M, Wang F, Wang Y, Ma X, Zhao M, Zhao C. Metabonomics study of the therapeutic mechanism of Gynostemma pentaphyllum and atorvastatin for hyperlipidemia in rats. PLoS One. 2013;8:e78731.

17. Muller C, Gardemann A, Keilhoff G, Peter D, Wiswedel I, Schild L. Prevention of free fatty acid-induced lipid accumulation, oxidative stress, and cell death in primary hepatocyte cultures by a Gynostemma pentaphyllum extract. Phytomedicine. 2012;19:395-401.

18. Qin R, Zhang J, Li C, Zhang X, Xiong A, Huang F, Yin Z, Li K, Qin W, Chen $M$, Zhang S, Liang L, Zhang $H$, Nie H, Ye W. Protective effects of gypenosides against fatty liver disease induced by high fat and cholesterol diet and alcohol in rats. Arch Pharm Res. 2012;35:1241-50.
19. Yan H, Wang $X$, Wang $Y$, Wang $P$, Xiao Y. Antiproliferation and antimigration induced by gypenosides in human colon cancer SW620 and esophageal cancer Eca-109 cells. Hum Exp Toxicol. 2014;33:522-33.

20. Liu J, Zhang L, Ren Y, Gao Y, Kang L, Qiao Q. Anticancer and immunoregulatory activity of Gynostemma pentaphyllum polysaccharides in H22 tumor-bearing mice. Int J Biol Macromol. 2014;69:1-4.

21. Cheng TC, Lu JF, Wang JS, Lin LJ, Kuo HI, Chen BH. Antiproliferation effect and apoptosis mechanism of prostate cancer cell PC-3 by flavonoids and saponins prepared from Gynostemma pentaphyllum. J Agric Food Chem. 2011;59:11319-29.

22. Li Y, Huang J, Lin W, Yuan Z, Feng S, Xie Y, Ma W. In vitro anticancer activity of a nonpolar fraction from Gynostemma pentaphyllum (Thunb.) Makino. Evid Based Complement Altern Med. 2016;2016:6308649.

23. Hou J, Liu S, Ma Z, Lang X, Wang J, Liang Z. Effects of Gynostemma pentaphyllum Makino on the immunological function of cancer patients. J Tradit Chin Med. 1991:11:47-52.

24. Tsui K-C, Chiang T-H, Wang J-S, Lin L-J, Chao W-C, Chen B-H, Lu J-F. Flavonoids from Gynostemma pentaphyllum exhibit differential induction of cell cycle arrest in H460 and A549 cancer cells. Molecules. 2014;19:17663-81.

25. Choi HS, Zhao TT, Shin KS, Kim SH, Hwang BY, Lee CK, Lee MK. Anxiolytic effects of herbal ethanol extract from Gynostemma pentaphyllum in mice after exposure to chronic stress. Molecules. 2013;18:4342-56.

26. Zhao TT, Shin KS, Choi HS, Lee MK. Ameliorating effects of gypenosides on chronic stress-induced anxiety disorders in mice. BMC Complement Altern Med. 2015;15:323.

27. Shin KS, Zhao TT, Choi HS, Hwang BY, Lee CK, Lee MK. Effects of gypenosides on anxiety disorders in MPTP-lesioned mouse model of Parkinson's disease. Brain Res. 2014;1567:57-65.

28. Lin C-C, Huang P-C, Lin J-M. Antioxidant and hepatoprotective effects of Anoectochilus formosanus and Gynostemma pentaphyllum. Am J Chin Med. 2000;28:87-96.

29. Liu ZL, Xie LZ, Zhu J, Li GQ, Grant SJ, Liu JP. Herbal medicines for fatty liver diseases. Cochrane Database Syst Rev. 2013;(8):CD009059. doi:10.1002/14651858.CD009059.pub2.

30. He Q, Li JK, Li F, Li RG, Zhan GQ, Li G, Du WX, Tan HB. Mechanism of action of gypenosides on type 2 diabetes and non-alcoholic fatty liver disease in rats. World J Gastroenterol. 2015;21:2058-66.

31. Megalli S, Davies NM, Roufogalis BD. Anti-hyperlipidemic and hypoglycemic effects of Gynostemma pentaphyllum in the zucker fatty rat. J Pharm Pharm Sci. 2006:9:281-91.

32. Lokman EF, Gu HF, Wan Mohamud WN, Ostenson CG. Evaluation of antidiabetic effects of the traditional medicinal plant Gynostemma pentaphyllum and the possible mechanisms of insulin release. Evid Based Complement Altern Med. 2015;2015:120572.

33. Circosta C, De Pasquale R, Occhiuto F. Cardiovascular effects of the aqueous extract of Gynostemma pentaphyllum Makino. Phytomedicine. 2005;12:638-43.

34. Purmova J, Opletal L. Phytotherapeutic aspects of diseases of the cardiovascular system. 5. Saponins and possibilities of their use in prevention and therapy. Ceska Slov Farm. 1995;44:246-51.

35. Tanner MA, Bu X, Steimle JA, Myers PR. The direct release of nitric oxide by gypenosides derived from the herb Gynostemma pentaphyllum. Nitric Oxide. 1999:3:359-65.

36. Yan H, Wang X, Niu J, Wang Y, Wang P, Liu Q. Anti-cancer effect and the underlying mechanisms of gypenosides on human colorectal cancer SW-480 cells. PLoS One. 2014;9:e95609.

37. Wu PK, Liu X, Hsiao WWL. The assessment of anti-cancer activities and saponin profiles of Gynostemma pentaphyllum saponins obtained from different regions of China. J Biotechnol. 2008;136:S85.

38. Juchi S. Preparation of a tea-like beverage containing Gynostemma pentaphyllum saponins. Osaka Yakuhin Kenkyusho KK Patent-Japan Kokai Tokkyo Koho-61. 1986;104:772.

39. Kenkyusho K. Saponins from Gynostemma pentaphyllum as health food supplements. Osaka Yakuhin assignee Jpn Kokai Tokkyo Koho JP. 60:85.

40. KK OYK. Rice vinegar containing saponins as health food supplement. Osaka Yakuhin Kenkyusho KK Patent-Japan Kokai Tokkyo Koho-60. 1985

41. Guo W, Wang W, editor. Cultivation and utilisation of Gynostemma pentaphyllum. Beijing: Publishing house of electronics; 1993.

42. Cui J, Eneroth P, Bruhn JG. Gynostemma pentaphyllum: identification of major sapogenins and differentiation from Panax species. Eur J Pharm Sci. 1999;8:187-91. 
43. Shi L, Song D, Pan M, Liu D. Research advances on the saponins of Gynostemma pentaphyllum. Drug Eval Res. 2011;34:456-64.

44. Piao XL, Xing SF, Lou CX, Chen DJ. Novel dammarane saponins from Gynostemma pentaphyllum and their cytotoxic activities against HepG2 cells. Bioorg Med Chem Lett. 2014;24:4831-3.

45. Yang F, Shi H, Zhang X, Yu LL. Two novel anti-inflammatory 21-nordammarane saponins from tetraploid jiaogulan (Gynostemma pentaphyllum). J Agric Food Chem. 2013;61:12646-52.

46. Nagai M. ea. Abstracts. In: The 23rd meeting of the Japanese Society of Pharmacognosy. 1976:37.

47. Takemoto T, Arihara S, Nakajima T, Okuhira M. Studies on the constituents of Gynostemma pentaphyllum Makino. II. Structures of gypenoside xv-xxi. Yakugaku Zasshi. 1983;103:1015-23.

48. Takemoto T, Arihara S, Yoshikawa K, Kusumoto K, Yano I, Hayashi T. Studies on the constituents of Cucurbitaceae plants. VI. On the saponin constituents of Luffa cylindrica Roem. Yakugaku Zasshi. 1984;104:246-55.

49. Takemoto T, Arihara S, Yoshikawa K. Studies on the constituents of Cucurbitaceae plants on the saponin constituents of Gynostemma pentaphyllum Makino. Yakugaku Zasshi. 1986;106:664-70.

50. Takemoto T, Arihara S, Nakajima T, Okuhira M. Studies on the constituents of Gynostemma pentaphyllum Makino structures of gypenoside ixiv. Yakugaku Zasshi. 1983:103:173-85.

51. Yoshikawa K, Arimitsu M, Kishi K, Takemoto T, Arihara S. Studies on the constituents of Cucurbitaceae plants on the saponin constituents of Gynostemma pentaphyllum Makino. Yakugaku Zasshi. 1987;107:361-6.

52. Yoshikawa K, Takemoto T, Arihara S. Studies on the constituents of Cucurbitaceae plants on the saponin constituents of Gynostemma pentaphyllum Makino. Yakugaku Zasshi. 1987;107:262-7.

53. Kim JH, Han YN. Dammarane-type saponins from Gynostemma pentaphyllum. Phytochemistry. 2011;72:1453-9.

54. Zhang XS, Zhao C, Tang WZ, Wu XJ, Zhao YQ. Gypensapogenin H, a novel dammarane-type triterpene induces cell cycle arrest and apoptosis on prostate cancer cells. Steroids. 2015;104:276-83.

55. Zhang XS, Cao JQ, Zhao C, Wang XD, Wu XJ, Zhao YQ. Novel dammarane-type triterpenes isolated from hydrolyzate of total Gynostemma pentaphyllum saponins. Bioorg Med Chem Lett. 2015;25:3095-9.

56. Shi L, Pi Y, Luo C, Zhang C, Tan D, Meng X. In vitro inhibitory activities of six gypenosides on human liver cancer cell line HepG2 and possible role of HIf-1 a pathway in them. Chem Biol Interact. 2015;238:48-54.

57. Liu J, Yang PY, Shi HM, Sun XJ, Lee SH, Yu LL. A novel Gynostemma pentaphyllum saponin and its adipogenesis inhibitory effect through modulating Wnt/ $\beta$-catenin pathway and cell cycle in mitotic clonal expansion. J Funct Foods. 2015:17:552-62.

58. Lee C, Lee JW, Jin Q, Jang H, Jang HJ, Rho MC, Lee MK, Lee CK, Lee MK, Hwang BY. Isolation and characterization of dammarane-type saponins from Gynostemma pentaphyllum and their inhibitory effects on IL6-induced STAT3 activation. J Nat Prod. 2015;78:971-6.

59. Xing SF, Jang M, Wang YR, Piao XL. A new dammarane-type saponin from Gynostemma pentaphyllum induces apoptosis in A549 human lung carcinoma cells. Bioorg Med Chem Lett. 2016;26:1754-9.

60. Liu J, Li YF, Shi HM, Wang T, Wu XL, Sun XJ, Yu LL. Components characterization of total tetraploid jiaogulan (Gynostemma pentaphyllum) saponin and its cholesterol-lowering properties. J Funct Foods. 2016:23:542-55.

61. Akihisa T, Tamura T, Matsumoto T. 14a-methyl-5a-ergosta-9 (11) 24 (28)-dien-3ß-ol a sterol from Gynostemma pentaphyllum. Phytochemistry. 1987;26:2412-3

62. Akihisa T, Kanari M, Tamura T, Matsumoto T. (24r)-and (24s)-14amethyl-5a-ergost-9 (11)-en-3ß-ols from Gynostemma pentaphyllum. Phytochemistry. 1989;28:1271-3.

63. Akihisa T, Mihara H, Fujikawa T, Tamura T, Matsumoto T. 24, 24-dimethyl5 a-cholestan-3 $\beta$-ol, a sterol from Gynostemma pentaphyllum. Phytochemistry. 1988;27:2931-3.

64. Akihisa T, Kokke W, Yokota T, Tamura T, Matsumoto T. 4a, 14a-dimethyl5a-ergosta-7, 9 (11), 24 (28)-trien-3ß-ol from Phaseolus vulgaris and Gynostemma pentaphyllum. Phytochemistry. 1990;29:1647-51.

65. Akihisa T, Tamura T, Matsumoto T, Kokke W, Yokota T. Isolation of acetylenic sterols from a higher plant. Further evidence that marine sterols are not unique. J Org Chem. 1989;54(606-10):0022-3263.
66. Akihisa T, Thakur S, Rosenstein FU, Matsumoto T. Sterols of cucurbitaceae: the configurations at c-24 of 24-alkyl-85-, 87 -and 88 -sterols. Lipids. 1986;21(39-47):0024-4201.

67. Akihisa T, Shimizu N, Tamura T, Matsumoto T. Structures of three new 24, 24-dimethyl- 87 -sterols from Gynostemma pentaphyllumfrom Gynostemma pentaphyllum. Lipids. 1986;21(515-7):0024-4201.

68. Song S-I, Ji A-g, Liang H, Wang W-L. Purification and structure analysis of polysaccharides from Gynostemma pentaphyllum (Thunb.) Makino. Zhong Yao Cai. 2008.

69. Li X-L, Wang Z-H, Zhao Y-X, Luo S-J, Zhang D-W, Xiao S-X, Peng Z-H. Purification of a polysaccharide from Gynostemma pentaphyllum Makino and its therapeutic advantages for psoriasis. Carbohydr Polym. 2012;89:1232-7.

70. Wang Z, Luo D. Antioxidant activities of different fractions of polysaccharide purified from Gynostemma pentaphyllum Makino. Carbohydr Polym. 2007;68:54-8.

71. Chi A-P, Chen J-P, Wang Z-Z, Xiong Z-Y, Li Q-X. Morphological and structural characterization of a polysaccharide from Gynostemma pentaphyllum Makino and its anti-exercise fatigue activity. Carbohydr Polym. 2008;74:868-74.

72. Tsai YC, Lin CL, Chen BH. Preparative chromatography of flavonoids and saponins in Gynostemma pentaphyllum and their antiproliferation effect on hepatoma cell. Phytomedicine. 2010;18:2-10.

73. Yin F, Hu L, Lou F, Pan R. Dammarane-type glycosides from Gynostemma pentaphyllum. J Nat Prod. 2004;67:942-52.

74. Fang Z-P, Zeng $X-Y$. Isolation and identification of flavonoid glycosides and organic acid from Gynostemma pentaphyllum (Thunb.) Makino. Zhongguo Zhong Yao Za Zhi. 1989;14:36.

75. Chang Q, Chen D, Shen L, Si J, Zhang J, Li X. Studies on the chemical constituents of Gynostemma pubescens (Gagnep.) C.Y. Wu i. Flavonoids. Nat Prod Res Dev. 1991:4:16-8.

76. Kao T, Huang S, Inbaraj BS, Chen B. Determination of flavonoids and saponins in Gynostemma pentaphyllum (Thunb.) Makino by liquid chromatography-mass spectrometry. Anal Chim Acta. 2008;626:200-11.

77. Nookabkaew S, Rangkadilok N, Prachoom N, Satayavivad J. Concentrations of trace elements in organic fertilizers and animal manures and feeds and cadmium contamination in herbal tea (Gynostemma pentaphyllum Makino). J Agric Food Chem. 2016;64:3119-26.

78. Deng S, Li X, Chen B, Deng F, Zhou X. Analysis of amino acids, vitamins and chemical elements in Gynostemma pentaphyllum (Thunb.) Makino. Hunan Yi Ke Da Xue Xue Bao. 1994:19:487-90.

79. Chen Y-G, Zhang Y. Isolation and characterization of benzyl-o- $\beta$-Dglucopyranoside from Gynostemma pentaphyllum. Yunnan Shi Fan Da Xue Xue Bao. 2001;21:58-9.

80. Z-I XU, F-q YANG, Z-n XIA. Chemical constituents of Gynostemma pentaphyllum. Nat Prod Res Dev. 2013;8:1067-9.

81. Zou C, Shi HM, Liu X, Sheng YQ, Ding TT, Yan J, Gao BY, Liu J, Lu WY, Yu LL. Conjugated linolenic acids and nutraceutical components in jiaogulan (Gynostemma pentaphyllum) seeds. LWT Food Sci Technol. 2016:68:111-8

82. Wang L, Wang XB, Wang P, Xiao YP, Liu QH. Optimization of supercritical carbon dioxide extraction, physicochemical and cytotoxicity properties of Gynostemma pentaphyllum seed oil: a potential source of conjugated linolenic acids. Sep Purif Technol. 2016:159:147-56.

83. Lin S. Research on the chemical constituents of Gynostemma pentaphyllum (Thunb.) Makino: Shenyang Pharmaceutical University; 2010.

84. Tsai YC, Wu WB, Chen BH. Preparation of carotenoids and chlorophylls from Gynostemma pentaphyllum (Thunb.) Makino and their antiproliferation effect on hepatoma cell. J Med Food. 2010;13:1431-42.

85. Shi L, Cao JQ, Shi SM, Zhao YQ. Triterpenoid saponins from Gynostemma pentaphyllum. J Asian Nat Prod Res. 2011;13:168-77.

86. Yin F, Zhang YN, Yang ZY, Hu LH. Nine new dammarane saponins from Gynostemma pentaphyllum. Chem Biodivers. 2006;3:771-82.

87. Chen T, Li B, Li Y, Zhao CD, Shen JM, Zhang HX. Catalytic synthesis and antitumor activities of sulfated polysaccharide from Gynostemma pentaphyllum Makino. Carbohydr Polym. 2011;83:554-60.

88. Li XL, Wang ZH, Zhao YX, Luo SJ, Zhang DW, Xiao SX, Peng ZH. Isolation and antitumor activities of acidic polysaccharide from Gynostemma pentaphyllum Makino. Carbohydr Polym. 2012;89:942-7. 
89. Lu KW, Chen JC, Lai TY, Yang JS, Weng SW, Ma YS, Lin HY, Wu RS, Wu KC, Wood WG, Chung JG. Gypenosides suppress growth of human oral cancer SAS cells in vitro and in a murine xenograft model: the role of apoptosis mediated by caspase-dependent and caspase-independent pathways. Integr Cancer Ther. 2012;11:129-40.

90. Hsu HY, Yang JS, Lu KW, Yu CS, Chou ST, Lin JJ, Chen YY, Lin ML, Chueh FS, Chen SS, Chung JG. An experimental study on the antileukemia effects of gypenosides in vitro and in vivo. Integr Cancer Ther 2011;10:101-12.

91. Lin J-J, Hsu H-Y, Yang J-S, Lu K-W, Wu RS-C, Wu K-C, Lai T-Y, Chen P-Y, Ma C-Y, Wood WG. Molecular evidence of anti-leukemia activity of gypenosides on human myeloid leukemia HL-60 cells in vitro and invivo using a $\mathrm{HL}-60$ cells murine xenograft model. Phytomedicine. 2011;18:1075-85.

92. Xu C, Wang B, Ren $\mathrm{S}$. The suppressive effect of gypenosides on murine s_ (180) sarcoma and cultured erythroleukemia cell line k_ (562). Xi'an Yi Ke Da Xue Xue Bao. 2002;23:217-9.

93. Kong L, Wang X, Zhang K, Yuan W, Yang Q, Fan J, Wang P, Liu Q. Gypenosides synergistically enhances the anti-tumor effect of 5-fluorouracil on colorectal cancer in vitro and in vivo: a role for oxidative stress-mediated DNA damage and p53 activation. PLoS One. 2015;10:e0137888.

94. Tai WC, Wong WY, Lee MM, Chan BD, Lu C, Hsiao WL. Mechanistic study of the anti-cancer effect of Gynostemma pentaphyllum saponins in the apc(min/+) mouse model. Proteomics. 2016;16:1557-69.

95. Chen L, Brar MS, Leung FC, Hsiao WL. Triterpenoid herbal saponins enhance beneficial bacteria, decrease sulfate-reducing bacteria, modulate inflammatory intestinal microenvironment and exert cancer preventive effects in ApcMin/+ mice. Oncotarget. 2016.

96. Chiranthanut N, Teekachunhatean S, Panthong A, Khonsung P, Kanjanapothi D, Lertprasertsuk N. Toxicity evaluation of standardized extract of Gynostemma pentaphyllum Makino. J Ethnopharmacol. 2013;149:228-34.

97. Du X-Y, Hou Y, Tan H, Han Y, Fan H. Studies on the anti-tumor activity of polysaccharide from Gynostemma pentaphyllum and its mechanism. Sci Technol Eng. 2009;20:5968-72.

98. Wang J-R, Zhao J-B. The effect of preventing recurrence of cancer metastasis on jiaogulan soup in clinical study. Zhejiang Zhong Yi Za Zhii. 1993;28:529-30.

99. Wang J-M, Wang J-R, Bi H-G, Fu G-X, Zhao J-B. Jiaogulan soup prevent recurrence of cancer metastasis on cancer patients after chemotherapy. Hebei Zhong Yi. 1997;19:23-4.

100. Yu S-Q, Wang J-R. Jiaogulan formula increase NK cell activity in breast cancer patients. Zhong Yi Yao Yan Jiu. 1997;13:7-8.

101. Wang J, Cao B. Immunological effects of jiaogulan granule in 19 cancer patients. Zhejiang Zhong Yi Za Zhi. 1989;24:449.

102. Liu S-X, Wang J-R. Experimental and clinical study on treatment of cancer with Gynostemma pentaphyllum Makin. Zhongguo Zhong Xi Yi Jie He Wai Ke Za Zhi 1996:110-1.

103. Zhou K, Bai S. The quality of randomized parallel controlled study of chemotherapy in advanced gastric cancer and improve survival of yiqi jianpi qingre huoxue method. Shiyong Zhongyi Neike Zazhi. 2015;29:42-4

104. Lu HF, Chen YS, Yang JS, Chen JC, Lu KW, Chiu TH, Liu KC, Yeh CC, Chen GW, Lin HJ, Chung JG. Gypenosides induced G0/G1 arrest via inhibition of cyclin e and induction of apoptosis via activation of caspases-3 and -9 in human lung cancer A-549 cells. In Vivo. 2008;22:215-21.

105. Chen J-C, Lu K-W, Lee J-H, Yeh C-C, Chung J-G. Gypenosides induced apoptosis in human colon cancer cells through the mitochondriadependent pathways and activation of caspase-3. Anticancer Res. 2006;26:4313-26.

106. Chen J-C, Lu K-W, Tsai M-L, Hsu S-C, Kuo C-L, Yang J-S, Hsia T-C, Yu C-S, Chou S-T, Kao M-C. Gypenosides induced G0/G1 arrest via CHk2 and apoptosis through endoplasmic reticulum stress and mitochondriadependent pathways in human tongue cancer scc-4 cells. Oral Oncol. 2009:45:273-83.

107. Wang QF, Chen JC, Hsieh SJ, Cheng CC, Hsu SL. Regulation of BCl-2 family molecules and activation of caspase cascade involved in gypenosides-induced apoptosis in human hepatoma cells. Cancer Lett. 2002;183:169-78

108. Wang QF, Chiang CW, Wu CC, Cheng CC, Hsieh SJ, Chen JC, Hsieh YC, Hsu SL. Gypenosides induce apoptosis in human hepatoma Huh-7 cells through a calcium/reactive oxygen species-dependent mitochondrial pathway. Planta Med. 2007;73:535-44.

109. Yang L, Wang P, Cheng XX, Zhang MY, Xiao YP. Suppressive effect of gypenosides on murine leukemia 11210 cell lines. Zhong Yao Cai. 2010;33:1588-92.

110. Sun D-P, Li X-X, Liu X-L, Zhao D, Qiu F-Q, Li Y, Ma P. Gypenosides induce apoptosis by $\mathrm{Ca}^{2+}$ overload mediated by endoplasmic-reticulum and store-operated $\mathrm{Ca}^{2+}$ channels in human hepatoma cells. Cancer Biother Radiopharm. 2013;28:320-6.

111. Lu KW, Chen JC, Lai TY, Yang JS, Weng SW, Ma YS, Tang NY, Lu PJ, Weng JR, Chung JG. Gypenosides causes DNA damage and inhibits expression of DNA repair genes of human oral cancer SAS cells. In Vivo. 2010;24:287-91.

112. Yuan G, Wei J, Zhou J, Guo X, Yang M. Apoptosis of human hepatoma cells induced by Gynostemma pentaphyllum Makino. Chin German J Clin Oncol. 2006;5:173-7.

113. Schild L, Chen BH, Makarov P, Kattengell K, Heinitz K, Keilhoff G. Selective induction of apoptosis in glioma tumour cells by a Gynostemma pentaphyllum extract. Phytomedicine. 2010;17:589-97.

114. Lu KW, Tsai ML, Chen JC, Hsu SCH, Hsia TC, Lin MW, Huang AC, Chang YH, Ip SW, Lu HF, Chung JG. Gypenosides inhibited invasion and migration of human tongue cancer SCC 4 cells through downregulation of NFKB and matrix metalloproteinase-9. Anticancer Res. 2008;28:1093-9.

115. Lu KW, Chen JC, Lai TY, Yang JS, Weng SW, Ma YS, Lu PJ, Weng JR, Chueh FS, Wood WG, Chung JG. Gypenosides inhibits migration and invasion of human oral cancer SAS cells through the inhibition of matrix metalloproteinase-2-9 and urokinase-plasminogen by ERK1/2 and NFKB signaling pathways. Hum Exp Toxicol. 2011;30:406-15.

116. Hanahan D, Weinberg RA. Hallmarks of cancer: the next generation. Cell. 2011;144:646-74

117. Hamanaka RB, Chandel NS. Targeting glucose metabolism for cancer therapy. J Exp Med. 2012;209:211-5.

118. Hsiao W, Tai WCS, Mo Z, Wu PK. The assessment of anti-cancer activities and saponin profiles of Gynostemma pentaphyllum saponins obtained from different regions of china. J Biotechnol. 2008;136:S22-3.

119. Yang $X B$, Zhao $Y$, Yang $Y$, Ruan $Y$. Isolation and characterization of immunostimulatory polysaccharide from an herb tea, Gynostemma pentaphyllum Makino. J Agric Food Chem. 2008;56:6905-9.

120. Liu X, Wang P-J, Xu F-X. Study on gypenosides inhibiting neoplasm growth and elevating immunological function in lewis lung cancer of mice. Anhui Zhong Yi Xue Yuan Xue Bao. 2001;1:21.

121. Ky PT, Huong PT, My TK, Anh PT, Kiem PV, Minh CV, Cuong NX, Thao NP, Nhiem NX, Hyun JH, Kang HK, Kim YH. Dammarane-type saponins from Gynostemma pentaphyllum. Phytochemistry. 2010;71:994-1001.

122. Shi L, Lu F, Zhao H, Zhao YQ. Two new triterpene saponins from Gynostemma pentaphyllum. J Asian Nat Prod Res. 2012;14:856-61.

123. Williams SA, Anderson WC, Santaguida MT, Dylla SJ. Patient-derived xenografts, the cancer stem cell paradigm, and cancer pathobiology in the 21st century. Lab Invest. 2013;93:970-82.

124. Tentler JJ, Tan AC, Weekes CD, Jimeno A, Leong S, Pitts TM, Arcaroli $\mathrm{J}$, Messersmith WA, Eckhardt SG. Patient-derived tumour xenografts as models for oncology drug development. Nat Rev Clin Oncol. 2012;9:338-50.

125. Siolas D, Hannon GJ. Patient-derived tumor xenografts: transforming clinical samples into mouse models. Cancer Res. 2013;73:5315-9.

126. Richmond A, Su Y. Mouse xenograft models vs gem models for human cancer therapeutics. Dis Model Mech. 2008;1:78-82.

127. Lin S, Jia-qing C, Hong Z, Yu-qing Z. A new triterpene saponin from Gynostemma pentaphyllum. Chin Herb Med. 2010;2:317.

128. Bai MS, Gao JM, Fan C, Yang SX, Zhang G, Zheng CD. Bioactive dammarane-type triterpenoids derived from the acid hydrolysate of Gynostemma pentaphyllum saponins. Food Chem. 2010;119:306-10.

129. Li N, Wu CF, Xu XY, Liu ZY, Li X, Zhao YQ. Triterpenes possessing an unprecedented skeleton isolated from hydrolyzate of total saponins from Gynostemma pentaphyllum. Eur J Med Chem. 2012;50:173-8.

130. Chen DJ, Liu HM, Xing SF, Piao XL. Cytotoxic activity of gypenosides and gynogenin against non-small cell lung carcinoma A549 cells. Bioorg Med Chem Lett. 2014;24:186-91.

131. Zhu H, Liu Z, Tang L, Liu J, Zhou M, Xie F, Wang Z, Wang Y, Shen S, Hu $L, Y u$ L. Reversal of P-gp and MRP1-mediated multidrug resistance 
by $\mathrm{H6}$, a gypenoside aglycon from Gynostemma pentaphyllum, in vincristine-resistant human oral cancer (kb/vcr) cells. Eur J Pharmacol. 2012;696:43-53.

132. Liu JS, Chiang TH, Wang JS, Lin LJ, Chao WC, Inbaraj BS, Lu JF, Chen BH. Induction of p53-independent growth inhibition in lung carcinoma cell a549 by gypenosides. J Cell Mol Med. 2015;19:1697-709.
133. Xie Z, Liu W, Huang H, Slavin M, Zhao Y, Whent M, Blackford J, Lutterodt $\mathrm{H}$, Zhou H, Chen P. Chemical composition of five commercial Gynostemma pentaphyllum samples and their radical scavenging, antiproliferative, and anti-inflammatory properties. J Agric Food Chem. 2010:58:11243-9.

\section{Submit your next manuscript to BioMed Central and we will help you at every step:}

- We accept pre-submission inquiries

- Our selector tool helps you to find the most relevant journal

- We provide round the clock customer support

- Convenient online submission

- Thorough peer review

- Inclusion in PubMed and all major indexing services

- Maximum visibility for your research

Submit your manuscript at

www.biomedcentral.com/submit 